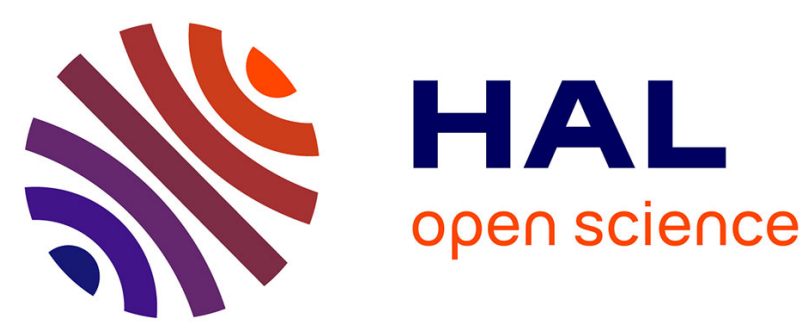

\title{
Smart designing of new hybrid materials based on brushite-alginate and monetite-alginate microspheres: Bio-inspired for sequential nucleation and growth
}

Walid Amer, Karima Abdelouahdi, Hugo Ronald Ramananarivo, Aziz Fihri, Mounir El Achaby, Mohamed Zahouily, Abdellatif Barakat, Kamal Djessas, James Clark, Abderrahim Solhy

\section{To cite this version:}

Walid Amer, Karima Abdelouahdi, Hugo Ronald Ramananarivo, Aziz Fihri, Mounir El Achaby, et al.. Smart designing of new hybrid materials based on brushite-alginate and monetite-alginate microspheres: Bio-inspired for sequential nucleation and growth. Materials Science and Engineering: C, 2014, 35, pp.341-346. 10.1016/j.msec.2013.11.012 . hal-01176910

\section{HAL Id: hal-01176910 \\ https://hal-univ-perp.archives-ouvertes.fr/hal-01176910}

Submitted on 26 Sep 2017

HAL is a multi-disciplinary open access archive for the deposit and dissemination of scientific research documents, whether they are published or not. The documents may come from teaching and research institutions in France or abroad, or from public or private research centers.
L'archive ouverte pluridisciplinaire HAL, est destinée au dépôt et à la diffusion de documents scientifiques de niveau recherche, publiés ou non, émanant des établissements d'enseignement et de recherche français ou étrangers, des laboratoires publics ou privés. 


\title{
Smart designing of new hybrid materials based on brushite-alginate and monetite-alginate microspheres: Bio-inspired for sequential nucleation and growth
}

\author{
Walid Amer ${ }^{\mathrm{a}}$, Karima Abdelouahdi ${ }^{\mathrm{b}}$, Hugo Ronald Ramananarivo ${ }^{\mathrm{a}}$, Aziz Fihri ${ }^{\mathrm{a}}$, Mounir El Achaby ${ }^{\mathrm{a}}$, \\ Mohamed Zahouily ${ }^{\mathrm{c}}$, Abdellatif Barakat ${ }^{\mathrm{d}}$, Kamal Djessas ${ }^{\mathrm{e}}$, James Clark ${ }^{\mathrm{f}}$, Abderrahim Solhy ${ }^{\mathrm{a}, *}$ \\ a MAScIR Foundation, INANOTECH, Rabat Design, Rue Mohamed El Jazouli, Madinat El Irfane 10100 Rabat, Morocco \\ b Centre National pour la Recherche Scientifique et Technique (CNRST), Division UATRS, Angle Allal Fassi/FAR, B.P. 8027, Hay Riad, 10000 Rabat, Morocco \\ ' Laboratoire de Matériaux, Catalyse et Valorisation des Ressources Naturelles, URAC 24, Faculté des Sciences et Techniques, Université Hassan II, Mohammedia B.P. 146, 20650, Morocco \\ d SUPAGRO-INRA-CIRAD-UMR IATE 1208, Ingenierie des Agropolymères et Technologies Emergentes, 2, Place Pierre Viala-Bât 31, 34060 Montpellier cedex 1, France \\ e CNRS-PROMES Tecnosud, F-66100 Perpignan, France \\ ${ }^{\mathrm{f}}$ Green Chemistry, Centre of Excellence, University of York, York YO10 5DD, UK
}

\section{A R T I C L E I N F O}

\section{Article history:}

Received 15 November 2012

Received in revised form 30 September 2013

Accepted 5 November 2013

Available online 19 November 2013

\section{Keywords:}

Hybrid materials

Biopolymers

Alginate

Phosphates

Brushite

Monetite

\begin{abstract}
A B S T R A C T
In this report new hybrid materials based on brushite-alginate and monetite-alginate were prepared by selfassembling alginate chains and phosphate source ions via a gelation process with calcium ions. The alginate served as nanoreactor for nucleation and growth of brushite or/and monetite due to its gelling and swelling properties. The alginate gel framework, the crystalline phase and morphology of formed hybrid biomaterials were shown to be strongly dependent upon the concentration of the phosphate precursors. These materials were characterized by thermogravimetric analysis (TGA), Fourier transform infrared spectroscopy (FTIR), X-ray diffraction (XRD), scanning electron microscopy (SEM) and energy dispersive X-ray analysis (EDX).
\end{abstract}

(C) 2013 Elsevier B.V. All rights reserved.

\section{Introduction}

Hybrid materials offer the opportunity to combine the desirable properties of an organic matrix with those of inorganic solids [1-3]. This material category has a diverse spectrum of applications ranging from pharmaceutical to wastewater treatment [4-6]. On the other hand, the calcium phosphate materials contain a multitude of crystalline phases and have attracted considerable interest both in the scientific community and industry due to their physico-chemical properties and their value in many fields of technology [7-17]. However, the combination of calcium phosphates and biopolymer can confer favorable mechanical properties, including strength due to the inorganic phase, toughness and plasticity due to the biopolymer phase. Biopolymers differ from each other in chemical composition, molecular weight, polydispersity, crystallinity, hydrophobicity, solubility, chain length, and thermal transitions [18]. Different biopolymer-calcium orthophosphate composites have been successfully obtained with alginate [19], chitosan $[20,21]$, cellulose [22] and starch [23,24]. Alginate is a natural polysaccharide extracted from the marine brown algae and it is composed of

\footnotetext{
* Corresponding author. Fax: + 212530279827.

E-mail address: a.solhy@mascir.com (A. Solhy).
}

two uronic acid monomers derived from mannose: the acid $\beta$-Lguluronic $(\mathrm{G})$ and the acid $\alpha$-D-mannuronic $(\mathrm{M})$ are linked by glycoside bonds $\beta-(1-4)$ and $\alpha-(1-4)$ (see Fig. S1 in Supporting information) $[25,26]$. Alginate gelation occurs when multivalent ions take their place between the $\mathrm{G}$ blocks of guluronic monomers, forming junctions of electrostatic nature, and the bond strength varies depending on the type of cation $[27,28]$. Most of the published works on hybrid composite alginate-calcium phosphate are based on preparation, nucleation and growth of apatite particles in a matrix of alginate biopolymer. In this context, Rajkumar et al. synthesized a nano-hydroxyapatite alginate nanocomposite with different weight percentages of sodium alginate; its biological and mechanical properties were studied [29]. Zhang et al. prepared a series of new nanocomposite beads of sodium alginate/ hydroxyapatite, in order to find a new way to slow drug release, but unfortunately they did not show the XRD spectra which can confirm if that it was really the hydroxyapatite or another phase [30].

Brushite (dicalcium phosphate dihydrate (DCPD)) and monetite (dicalcium phosphate (DCP)) cements have raised considerable interest in the last decade, because they are metastable under physiological conditions and can be resorbed more quickly than hydroxyapatite cements [31]. Several authors have suggested that it's a precursor of bone mineralization, including biological apatites [32,33]. The brushite has been 
widely used in the reconstruction materials, dental cements, as well as in formulation chemistry $[34,35]$. These phosphates are usually synthesized in an aqueous medium by double decomposition of a calcium salt and a phosphate salt or by neutralization of phosphoric acid in lime [36,37]. Other routes have been also explored to synthesis these calcium phosphates such as sol-gel [38], solid state [39], chemical precipitation [40], hydrothermal [41], hard templating [42], flame-spray route [43], dual irradiation of the microwave and ultrasound [44], and physiological conditions [45]. More recently, Gomez-Morales et al. have controlled the precipitation of calcium phosphate such as brushite by using vapor diffusion method in microdroplets and amino acids like organic additives [46].

This current study demonstrates for the first time that the synthesis of hybrid material phosphate-biopolymer can be achieved using gelation of alginate mixed with a phosphate source via complexation of calcium ions. The synthetic protocol reported here takes advantage of the controlled gelation of the mixture of brushite or monetite structure at room temperature.

\section{Experimental section}

\subsection{Chemical reagents}

$\left(\mathrm{NH}_{4}\right)_{2} \mathrm{HPO}_{4}$ and $\mathrm{Ca}\left(\mathrm{NO}_{3}\right)_{2} \cdot 4 \mathrm{H}_{2} \mathrm{O}$ were purchased from Aldrich and used as a precursor of the $\mathrm{HPO}_{4}^{2-}$ ligand and for gelation, respectively. Other phosphate sources are also tested namely: sodium phosphate dibasic $\left(\mathrm{Na}_{2} \mathrm{HPO}_{4}\right)$ and ammonium phosphate monobasic $\left(\mathrm{NH}_{4} \mathrm{H}_{2} \mathrm{PO}_{4}\right)$. Sodium alginate was purchased from Aldrich and used as supplied. Deionized water was used in all experiments.

\subsection{Synthesis of hybrid materials}

Hydrogel material was achieved via complexation of alginate/ phosphate by calcium ion (Fig. S2). Aqueous solutions of phosphorus precursor were prepared by dissolving different amounts of $\left(\mathrm{NH}_{4}\right)_{2} \mathrm{HPO}_{4}: 0.1,0.3,0.5$, and $1 \mathrm{M}$ into $100 \mathrm{~mL}$ of distilled water, and then sodium alginate was added to diammonium phosphate solution with a concentration of $1 \%$. The mixture was stirred for $1 \mathrm{~h}$ at room temperature. This gel was added dropwise using a syringe with a $0.8 \mathrm{~mm}$ diameter needle at room temperature to the stirred $\mathrm{Ca}\left(\mathrm{NO}_{3}\right)_{2} \cdot 4 \mathrm{H}_{2} \mathrm{O}$ solution $(0.25 \mathrm{M})$. The formed beads immediately are abandoned overnight to ensure effective diffusion of calcium ions, and thereafter the homogeneity of the system and the growth of hybrid materials.
After that, the beads were filtered with a 100 mesh screen, and washed three times with distilled water to remove the $\mathrm{Ca}^{2+}$ excess and impurities on the beads surface. In the end, the beads were dried at room temperature for $24 \mathrm{~h}$ before various characterizations. For different $\left(\mathrm{NH}_{4}\right)_{2} \mathrm{HPO}_{4}$ concentration $(0.1,0.3,0.5$ and $1 \mathrm{M})$, the dried hybrid materials will be henceforth identified as Phos-Alg_1 (phosphatealginate), Phos-Alg_2, Phos-Alg_3, and Phos-Alg_4 respectively.

\subsection{Thermal and structural characterization techniques}

TGA were conducted under air in a TA Instrument Q500 apparatus with a $10{ }^{\circ} \mathrm{C} / \mathrm{min}$ ramp between 25 and $1000{ }^{\circ} \mathrm{C}$. X-ray diffraction patterns of the samples were obtained at room temperature on a Bruker AXS D-8 diffractometer using $\mathrm{Cu}-\mathrm{K} \alpha$ radiation in Bragg-Brentano geometry $(\theta-2 \theta)$. Fourier transform infrared spectra of samples in $\mathrm{KBr}$ pellets were measured on a Bruker Vector 22 spectrometer. Scanning electron microscopy pictures were recorded on a FEI Quanta 200 microscope after carbon metallization.

\section{Results and discussion}

In order to conduct this study, we investigated several parameters, especially the concentration of phosphate precursor and the drying temperature, that influence the nucleation and growth of the inorganic matrix and obviously the hybrid material by afterwards. Thus, the concentration of the precursor of the phosphate plays an important role in the appearance of the prepared hybrid xerogels. Fig. 1 shows pictures taken by a digital camera and SEM at low magnification of the as synthesized hybrid xerogel microspheres (Phos-Alg_1 and Phos-Alg_2), micro-lentils (Phos-Alg_3) and granulated powder (Phos-Alg_4). This change in the external shape can be explained by the increase of the concentration of $\mathrm{HPO}_{4}^{2-}$ ligand which occupies the space in the alginate chains and subsequently distorts the spherical shape of the droplet.

The XRD patterns have been used to investigate the phases in our hybrid xerogels at different phosphate concentrations. Fig. 2 shows diagrams of the samples such as Phos-Alg_1, Phos-Alg_2, Phos-Alg_3 and Phos-Alg_4 corresponding to $\left(\mathrm{NH}_{4}\right)_{2} \mathrm{HPO}_{4}$ concentrations: $0.1 \mathrm{M}$, $0.3 \mathrm{M}, 0.5 \mathrm{M}$ and $1 \mathrm{M}$ respectively. The Phos-Alg_1 is poorly crystalline maybe because the amount of phosphates is poor, but has a pure brushite phase or dicalcium phosphate dihydrate with monoclinic crystal structure (JCPDS 4-013-3344). Brushite crystallized in the monoclinic system (space group Ia) with the crystallographic parameters $\mathrm{a}=6.239 \AA, \mathrm{b}=15.180 \AA, \mathrm{c}=5.812 \AA, \alpha=\gamma=90^{\circ}$ and
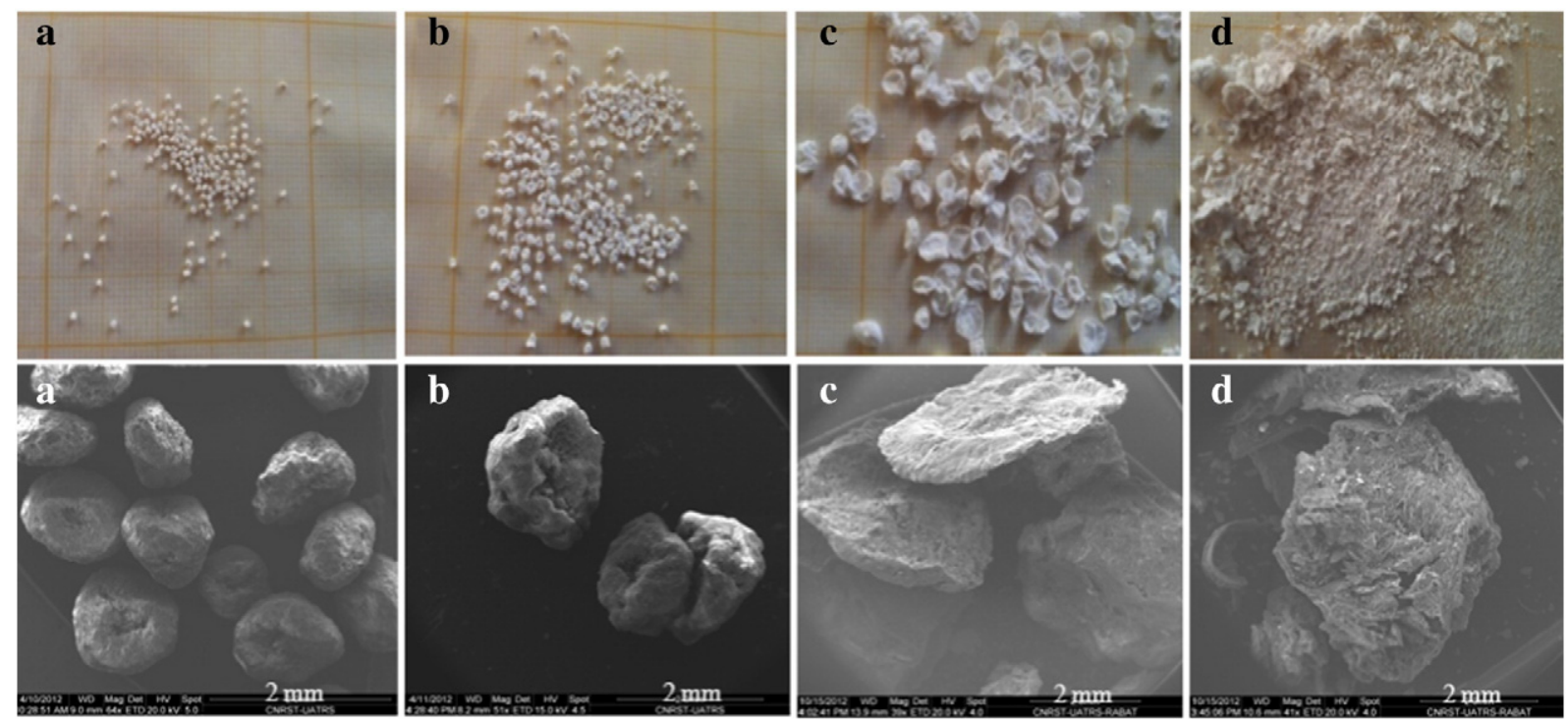

Fig. 1. Digital photographs and low-magnification SEM images of hybrid beads Phos-Alg_1 (a), Phos-Alg_2 (b), Phos-Alg_3 (c) and Phos-Alg_4 (d). 


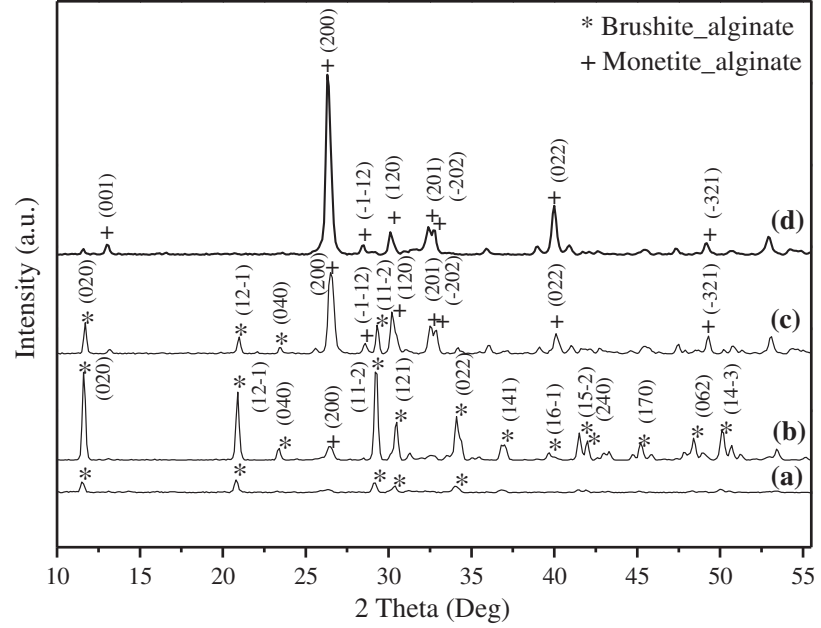

Fig. 2. XRD patterns of hybrid materials: Phos-Alg_1 (a), Phos-Alg_2 (b), Phos-Alg_3 (c) and Phos-Alg_4 (d).

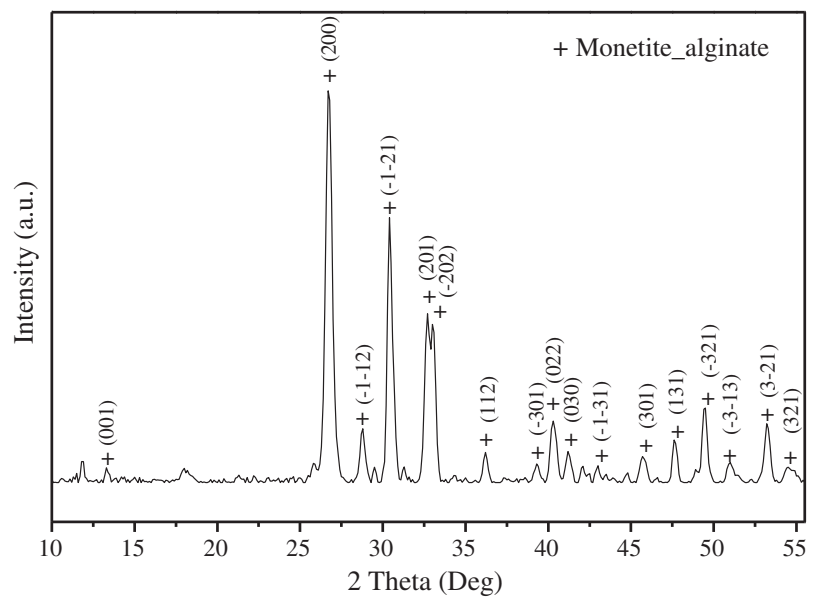

Fig. 3. XRD pattern of dried hybrid materials (Phos-Alg_2 and Phos-Alg_3) overnight at $100{ }^{\circ} \mathrm{C}$. $\beta=116^{\circ} 42^{\prime}$ [47]. The intensity of the diffraction peaks indicates that the sample Phos-Alg_2 is well crystallized. This is made up of a brushite phase with trace amount of monetite or dicalcium phosphate with triclinic crystal (JCPDS 4-009-4184). The Phos-Alg_3 represents a coexistence of both phases which is confirmed by the high intensity of diffraction peaks of the monetite $\{020\}$ facet and brushite $\{200\}$ facet. Finally, the Phos-Alg_4 sample is composed predominantly of the monetite phase. Monetite crystallized in the triclinic system (space group $P-1$ ) with the crystallographic parameters: $a=6.91 \AA$, $\mathrm{b}=6.998 \AA, \mathrm{c}=6.627 \AA, \alpha=96.34^{\circ}, \beta=91.67^{\circ}$ and $\gamma=76.18^{\circ}$. The concentration of $\left(\mathrm{NH}_{4}\right)_{2} \mathrm{HPO}_{4}$ plays a crucial role in the growth of inorganic phases. The selectivity for DCPD or DCP was clearly influenced when the amount of phosphate in the alginate matrix was increased. The oversaturation of alginate matrix by phosphate leads to a high percentage of the monetite phase in Phos-Alg_4. High concentrations of phosphate source favor monetite formation (Fig. S3). This can be explained by increased steric hindrance exerted on the alginate fibers by ligand $\mathrm{HPO}_{4}^{2-}$, which will reduce necessary space for keeping the structural water. We have also studied the influence of the drying temperature on samples: Phos-Alg_2 and Phos-Alg_3. The analysis of these bio-composites dried at $100{ }^{\circ} \mathrm{C}$ overnight by XRD shows that we have a total selectivity to synthesis monetite (Fig. 3 ). This can be explained by the conversion of brushite phase into monetite, which is simply due to the dehydration of brushite (removal of water molecules from the structure). Thus we can get simply the monetite phase by increasing the drying temperature. It's also noteworthy that the use of other sources of $\mathrm{HPO}_{4}^{2-}$ ligand gives similar results. The semi-qualitative analysis by energy dispersive spectroscopy (EDAX) was carried out, when taking SEM photographs (Fig. S4). The study allowed us to demonstrate the presence of the chemical elements that constitute calcium phosphates: i) phosphorus, ii) oxygen, and ii) calcium. The data from semi-qualitative analysis give us an idea as to the composition of xerogels prepared in terms of molar ratio $\mathrm{Ca} / \mathrm{P}$. The results of the $\mathrm{Ca} / \mathrm{P}$ ratio are in the range of: $1.12,0.94,0.97$ and 1.24 for Phos-Alg_1, Phos-Alg_2, Phos-Alg_3 and Phos-Alg_4 respectively. These values are consistent with the molar ratio of brushite and monétite $\mathrm{Ca} / \mathrm{P}=1$ reported in the literature.

The crystal unit cell contains four motifs of $\mathrm{CaHPO}_{4} \cdot 2 \mathrm{H}_{2} \mathrm{O}$ and the structure is shown in Fig. 4. The latter shows that the crystals are composed of brushite corrugated sheets of composition $\mathrm{CaHPO}_{4}$, arranged in parallel to each other, normal to the axis b and linked together by a double layer of water molecules. In the same way, Fig. 5 gives a projection of monetite viewed along the b-axis. This projection shows the spatial

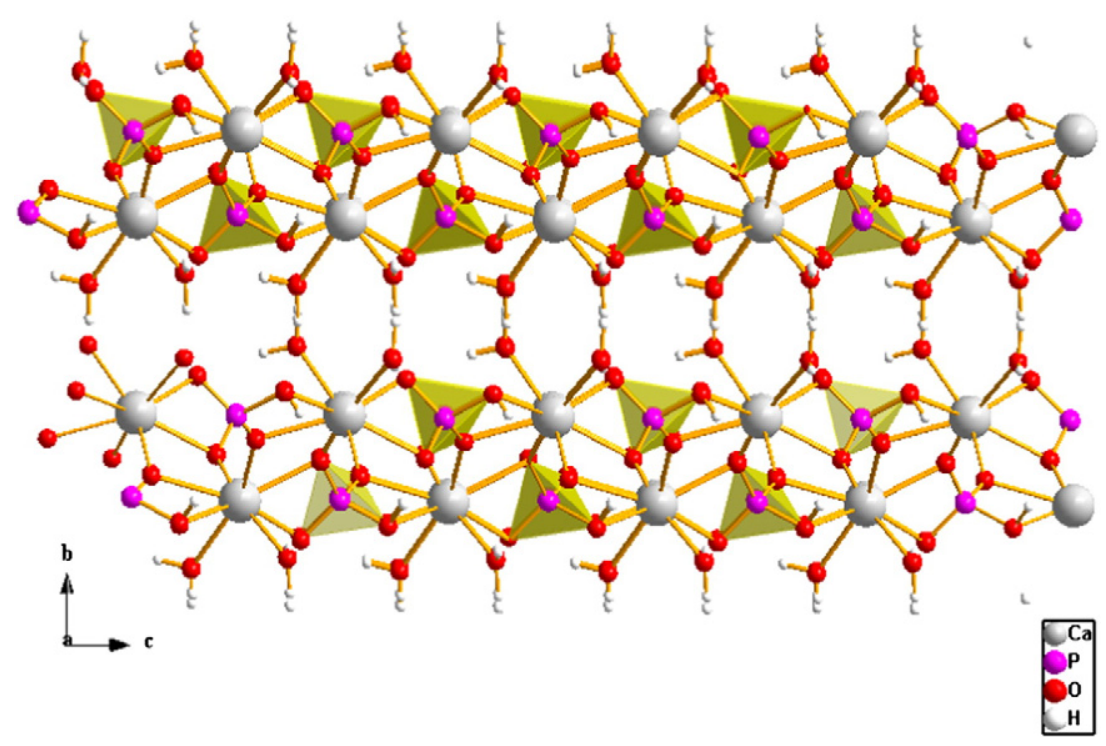

Fig. 4. Projection view of brushite. 


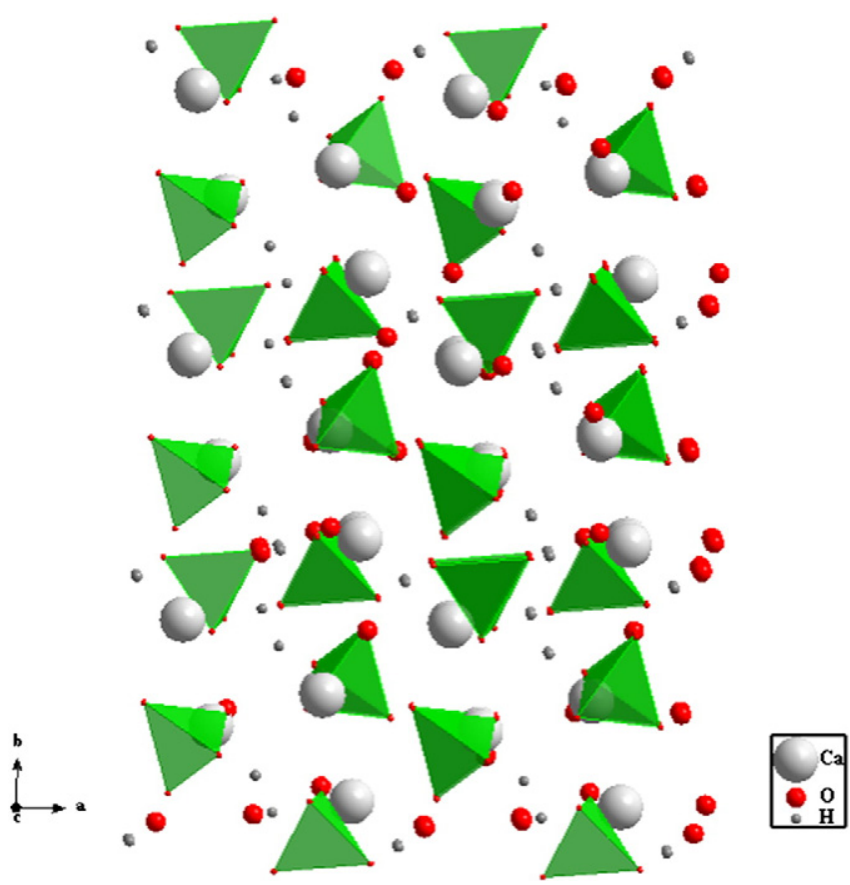

Fig. 5. Projection view of monetite.

distribution and the unit cell of monetite illustrating the sequence of $\mathrm{PO}_{4}$ units and the location of calcium ions within the framework.

Fig. 6 shows the FT-IR spectra of the hybrid composite beads. The absorptions observed at $1421 \mathrm{~cm}^{-1}$ in all samples are due to the symmetric and asymmetric stretching modes of the $\mathrm{COO}^{-}$bands from the carboxylate groups $[48,49]$. The spectra of Phos-Alg_1, Phos-Alg_2, and Phos-Alg_3 exhibit similar bands. Brushite is characterized by the $\mathrm{O}-\mathrm{H}$ stretching modes of the crystallization water and also for alginate matrix, with two peak doublets, respectively, 3550 and $3466 \mathrm{~cm}^{-1}$ [48]. The $\mathrm{H}-\mathrm{O}-\mathrm{H}$ bending gives rise to absorption at $1651 \mathrm{~cm}^{-1}$ [50]. The main IR bands characterizing the $\mathrm{PO}_{4}$ group can be detected at 1128 , 1059 and 998, and $1012 \mathrm{~cm}^{-1}$, due to $\mathrm{PO}$ stretching modes of the $\mathrm{PO}_{4}$ fragment [50]. Weaker sharp bands at 1210 and 871 , and $875 \mathrm{~cm}^{-1}$ are due, respectively, to the $\mathrm{P}-\mathrm{O}-\mathrm{H}$ stretching mode and the $\mathrm{P}-\mathrm{OH}$ bending mode [51]. Bands at frequencies 521,590, and $650 \mathrm{~cm}^{-1}$ are assigned mainly to PO deformation modes of the tetrahedral $\mathrm{PO}_{4}$ group [52]. The FTIR also identifies the functional groups of

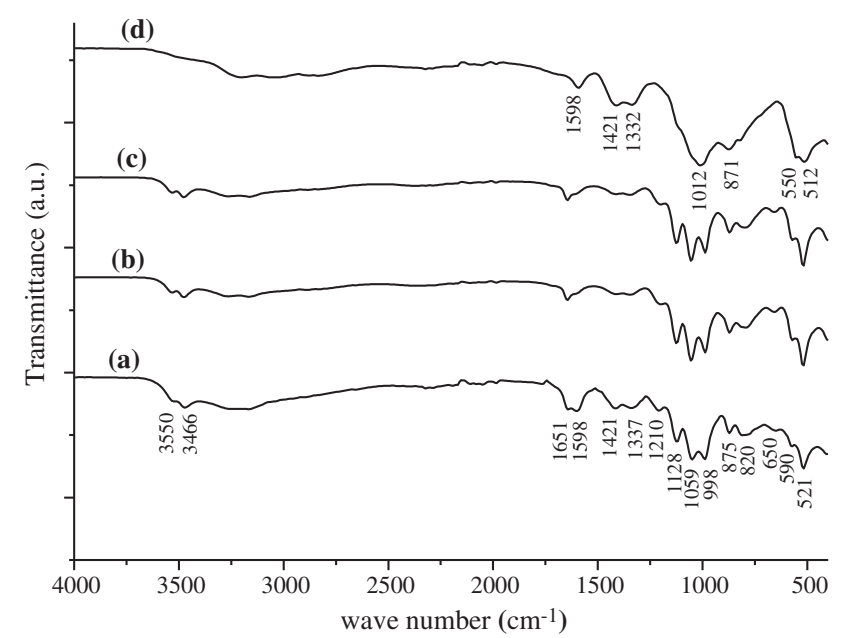

Fig. 6. FT-IR spectra of hybrid beads: Phos-Alg_1 (a), Phos-Alg_2 (b), Phos-Alg_3 (c) and Phos-Alg_4 (d).
C-monetite sample [53], water vibrations at 3550 and $3466 \mathrm{~cm}^{-1}$ are not seen in the spectrum of samples "d" corresponding to Phos-Alg_4.

Morphologies of the hybrid bio-composites are shown in Fig. 7. These show that the morphology of the crystals prepared by this route is very much dependent on the precursor concentration. Fig. 7a shows the SEM image of Phos-Alg_1, where the inorganic matrix is the brushite crystal prepared with $0.1 \mathrm{M}$ of the $\left(\mathrm{NH}_{4}\right)_{2} \mathrm{HPO}_{4}$ solution. The morphology of the crystal is small plate-like and needle-like structures with a heterogeneous size. Fig. 7b presents the SEM image of PhosAlg_2, where the inorganic matrix is a mixture of the brushite and monetite crystals prepared with $0.3 \mathrm{M}$. This image consists of heterogeneous shapes like the first sample. In contrast, the platelet arrangement shown in Fig. 7c, which was prepared with $0.5 \mathrm{M}$ concentration of $\mathrm{HPO}_{4}^{2-}$ ligand, gives rise to this single morphology with homogeneous dimensions, even though we have two phases. Generally, for the first three samples (a), (b) and (c), the morphology consists of merged platelets forming irregular chunky materials with various dimensions (a), (b) and (c). The fast rate of nucleation and crystal growth as a result of the high precursor concentration led to better defined plate-like structures corresponding to the predominant brushite crystals [54]. Finer spherical-like monetite particles are formed when we have increased the source concentration of $\mathrm{HPO}_{4}^{2-}$ ligand $(1 \mathrm{M})$. The morphology of monetite crystals is similar to snowball flowers with a size at around $2 \mu \mathrm{m}$ (Fig. 7d).

The thermal behavior of these dried beads was investigated by thermogravimetric analysis. The curves (Fig. 8a, b, c and d) showed different profiles characterized by different ranges of thermal degradation. These thermograms (a, b, c, d) showed continuous weight loss in the range of $25-330{ }^{\circ} \mathrm{C}$ and $330-750{ }^{\circ} \mathrm{C}$. The first weight loss at ca. $200{ }^{\circ} \mathrm{C}$ can be assigned to the loss of absorbed water that can lead to conversion of DCPD to DCP [54] and also the conversion of DCP to calcium pyrophosphate $\left(\mathrm{Ca}_{2} \mathrm{P}_{2} \mathrm{O}_{7}(\mathrm{CCP})\right)[53,55]$. These observations were confirmed by the analysis of inorganic materials recovered after calcination at $750{ }^{\circ} \mathrm{C}$ by XRD and FTIR (Figs. 9 and 10). The weight loss shown by the curve (a) at $750{ }^{\circ} \mathrm{C}$ is around $4 \%$ and can be explained by thermal degradation of amorphous carbon. The total weight loss was found to be around 55\%, 37\%, 27\% and 19\% as shown in Fig. 8 (a, b, c and d) respectively, these results prove that increasing the amount of phosphate in an alginate gel matrix leads to decrease of the mass loss directly causing the formation of $\beta$-TCP and CCP.

From a mechanistic point of view, the fact that the mixture of the phosphate source with alginate gives rise to a homogeneous gel, suggests an interaction between the biopolymer and the $\mathrm{HPO}_{4}^{2-}$. The stability and homogeneity of this gel can be explained by the possible interactions between the $\mathrm{HPO}_{4}^{2-}$ ligand and the carboxylate group of the alginate. This physical bonding translates to mixtures that are rich in electronic pairs showing higher reactivity and mineralization potential to be transformed into hybrid hydrogel materials. When the mixture of alginate and phosphate source meets the solution of $\mathrm{Ca}^{2+}$, divalent ions, interchain cross-linking occurs as a result of calcium coordination with pliers formed by two phosphated GG blocks as the "egg-box" model [56-58]. In addition, the nucleation and the growth of brushite and monetite can be due to interactions between inorganic minerals and alginate chains in the biopolymer. These observations are in agreement with those reported by M. Rajkumar [29].

\section{Conclusions}

In summary, a new type of hybrid materials was obtained via a straightforward synthetic route with alginate biopolymer as organic matrix and phosphate source ions with calcium ions. All the synthesis has been carried out at room temperature; thus greatly expanding the applicability of the method for the preparation of materials loaded with thermally unstable substances. Four hybrid beads were prepared with different inorganic filler contents. Structure and physicochemical characterization of these hybrid phosphates were evaluated by FT-IR, 

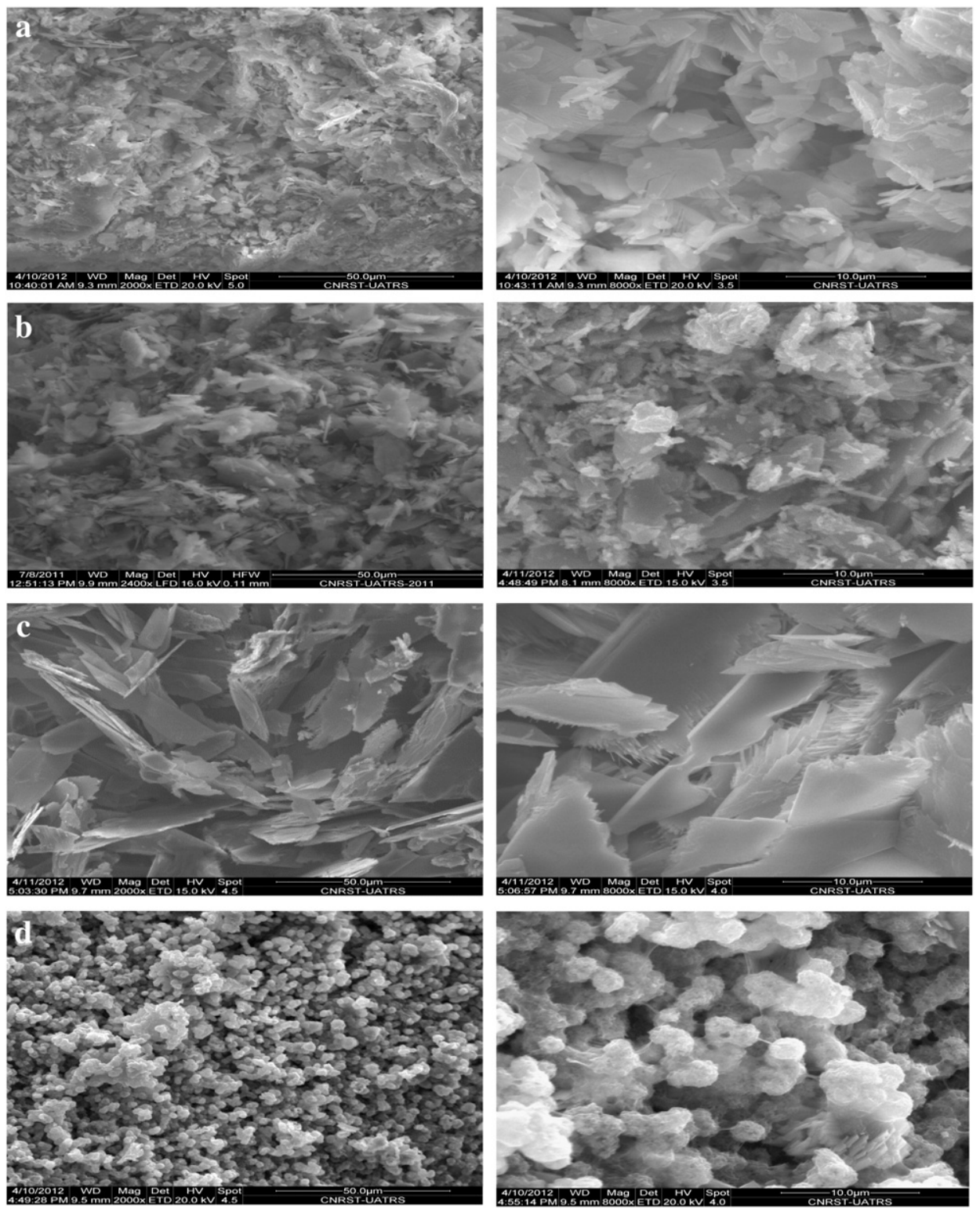

Fig. 7. SEM micrographs of hybrid xerogels: Phos-Alg_1 (a), Phos-Alg_2 (b), Phos-Al_3 (c) and Phos-Alg_4 (d).

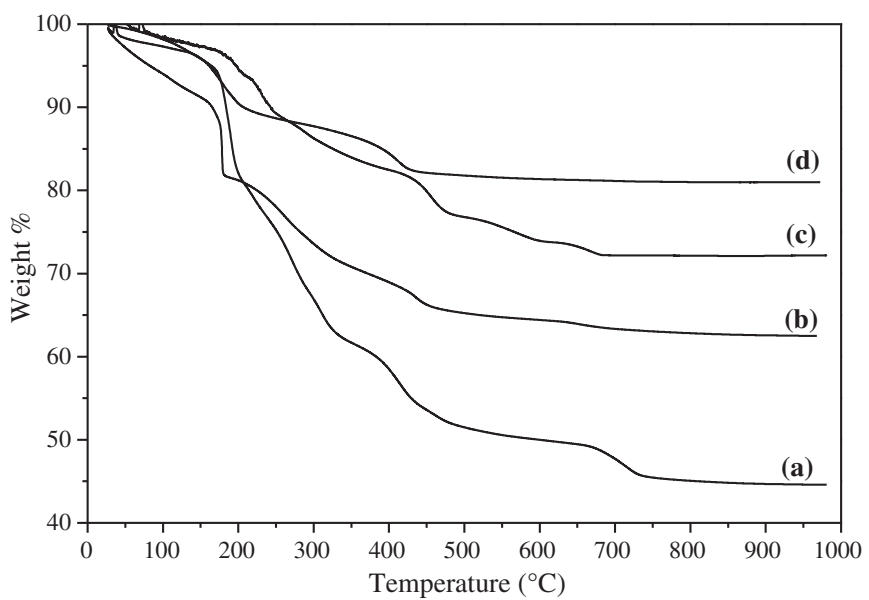

Fig. 8. Thermogravimetric curves for hybrid xerogels: Phos-Alg_1 (a), Phos-Alg_2 (b), Phos-Alg_3 (c) and Phos-Alg_4 (d).

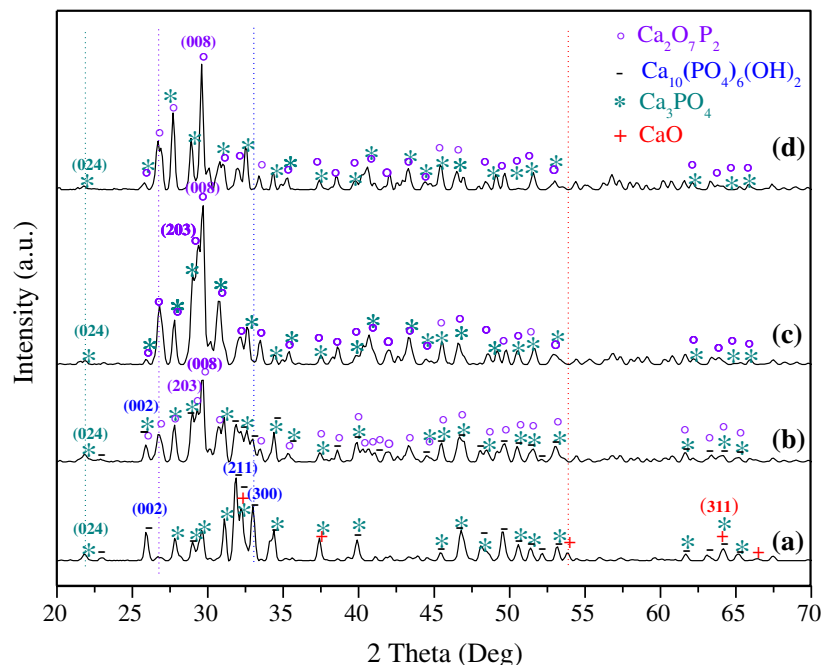

Fig. 9. XRD patterns of calcined beads at $750{ }^{\circ} \mathrm{C}$ 


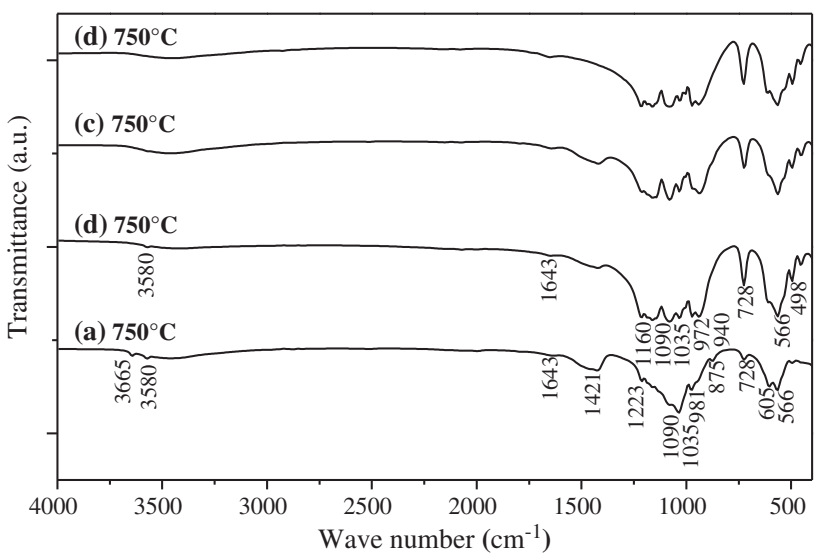

Fig. 10. FT-IR spectrum of calcined beads at $750{ }^{\circ} \mathrm{C}$.

XRD, SEM and TGA. Experimental results for all hybrid materials indicated that the phosphate source concentration is a predominant factor for the sequential nucleation and growth and also the crystalline selectivity. The structural characterization results suggested that the particles formed into the biopolymeric matrix are brushite and/or monetite. Moreover, the observation of particle morphology by SEM proved that the shape changes according to the concentration of phosphate. The thermal behavior of these materials depends on the amount of water physisorbed, or structural, and the phosphate concentration. Characterization of the recovered phosphates after heat treatment reveals the formation of a mixture of several types of calcium phosphate. Studies of the applications of these materials are underway in our laboratory.

\section{Acknowledgments}

The financial assistance of the Office Chérifien des Phosphates in the Moroccan Kingdom (OCP Group): R\&D Department towards this research is hereby acknowledged. The authors are also grateful to Mr. Mohamed Lasry for his help to achieve this work within the framework of the IMEDER and AMISOLE. Warm thanks are due to Dr. Mohamed Oudanane and for his admirable team from the clinic of the United Nations in Rabat for the professional qualifications and the kindness that they have shown during my hospitalization and for my successful surgery.

\section{Appendix A. Supplementary data}

Supplementary data to this article can be found online at http://dx. doi.org/10.1016/j.msec.2013.11.012.

\section{References}

[1] A.P. Wight, M.E. Davis, Chem. Rev. 102 (2002) 3589-3614.

[2] Z. Ahmad, J.E. Mark, Mater. Sci. Eng. C 6 (1998) 183-196.

[3] S.V. Dorozhkin, M. Epple, Angew. Chem. Int. Ed. 41 (2002) 3130-3146.

[4] M.F. Ashby, Y.J.M. Bréchet, Acta Mater. 51 (2003) 5801-5821.

[5] L. Nicole, L. Rozes, C. Sanchez, Adv. Mater. 22 (2012) 3208-3214.
[6] K.E. Lee, N. Morad, T.T. Teng, B.T. Poh, Chem. Eng. J. 203 (2012) 370-386.

[7] G.S. Sailaja, S. Velayudhan, M.C. Sunny, K. Sreenivasan, H.K. Varma, P. Ramesh, J. Mater. Sci. 38 (2003) 3653-3662.

[8] A. Solhy, W. Amer, M. Karkouri, R. Tahir, A. El Bouari, A. Fihri, M. Bousmina, M. Zahouily, J. Mol. Catal. A Chem. 336 (2011) 8-15.

[9] P. Becker, Phosphates and phosphoric acid: raw materials technology and economics of the wet process, Fertilizer Science and Technology Series, 2nd ed., Marcel Dekker, New York, 1989, p. 6.

[10] L.L. Hench, J. Am. Ceram. Soc. 81 (1998) 1705-1728.

[11] F.C.M. Driessens, M.G. Boltong, O. Bermu dez, J.A. Planell, M.P. Ginebra, E. Fernandez J. Mater. Sci. Mater. Med. 5 (1994) 164-170.

[12] K.A. Hing, S.M. Best, K.E. Tanner, W. Bonfield, P.A. Revell, J. Biomed. Mater. 68 (2004) 187-200.

[13] D.C. Fredericks, J.A. Bobst, E.B. Petersen, J.V. Nepola, J.E. Dennis, A.I. Caplan, A.V. Burgess, R.J. Overby, O.H. Schulz, Orthopedics 27 (2004) S167-S173.

[14] M. Komath, Bull. Mater. Sci. 26 (2003) 415-422.

[15] A.K. Cherian, A.C. Rana, S.K. Jain, Drug Dev. Ind. Pharm. 26 (2000) 459-463.

[16] S. Patil, S.S. Pancholi, S. Agrawal, G.P. Agrawal, Drug Deliv. 11 (2004) 193-199.

[17] I. Roy, S. Mitra, A. Maitra, S. Mozumdar, Int. J. Pharm. 250 (2003) 25-33.

[18] S.M. Rea, W. Bonfield, J. Am. Ceram. Soc. (2004) 40-43.

[19] O. Smidsrod, K. Draget, Carbohydr. Eur. 14 (1996) 6-13.

[20] K.D. Patel, A. El-Fiqi, H.-Y. Lee, R.K. Singh, D.-A. Kim, H.-H. Lee, H.-W. Kim, J. Mater. Chem. 22 (2012) 24945-24956.

[21] Q. Hu, B.Q. Li, M. Wang, J.C. Shen, Biomaterials 25 (2004) 779-785.

[22] J. Liuyun, L. Yubao, X. Chengrong, J. Biomed. Sci. 16 (65) (2009) 1-10.

[23] A.P.T. Marques, R.L. Reis, Mater. Sci. Eng. C 25 (2005) 215-229.

[24] I.B. Leonora, A. Itob, K. Onumab, N. Kanzakib, R.L. Reisa, Biomaterial 24 (2003) 579-585.

[25] E.C.C. Stanford, Chem. News 47 (1883) 254-267.

[26] S.N. Pawar, K.J. Edgar, Biomaterials 33 (2012) 3279-3305.

[27] A. Haug, O. Smidsrod, Acta Chem. Scand. 24 (1970) 843-854.

[28] E. Torres, Y.N. Mata, M.L. Blazquez, J.A. Munoz, F. Gonzalez, A. Ballester, Langmuir 21 (2005) 7951-7958.

[29] M. Rajkumar, N. Meenakshisundaram, V. Rajendran, Mater. Charact. 62 (2011) 469-479.

[30] J. Zhang, Q. Wang, A. Wang, Acta Biomater. 6 (2009) 319-714.

[31] G. Vereecke, J. Lemaître, J. Cryst. Growth 104 (1990) 820-832.

[32] A.H. Roufosse, W.J. Landis, W.K. Sabine, M.J. Glimcher, J. Ultrastruct. 68 (1979) $235-255$.

[33] M.J. Glimcher, L.C. Bonar, M.D. Grynpas, W.J. Landis, A.H. Roufosse, J. Crystal. Growth 53 (1981) 100-119.

[34] A.A. Mirtchi, J. Lemaître, N. Terao, Biomaterials 107 (1989) 475-480.

[35] S.V. Dorozhkin, Materials 2 (2009) 399-498.

[36] A.T. Jensen, J. Rathlev, Inorg. Synth. 4 (1953) 19-22.

[37] P.D.S. St Pierre, J. Am. Chem. Soc. 77 (1955) 2197-2198.

[38] Y. Tokuoka, Y. Ito, K. Kitahara, Y. Niikura, A. Ochiai, N. Kawashima, Chem. Lett. 35 (2006) 1220-1221.

[39] G. Thomas, H. Dehbi, Mater. Chem. Phys. 15 (1986) 1-13.

[40] R.I. Martin, P.W. Brown, J. Cryst. Growth 183 (1998) 417-426.

[41] Y. Fujishiro, H. Yabuki, K. Kawamura, T. Sato, A. Okuwaki, J. Chem. Technol. Biotechnol. 57 (1993) 349-353.

[42] H. Lim, A. Kassim, N. Huang, R. Hashim, S. Radiman, P. Khiewe, W. Chiu, Ceram. Int 35 (2009) 2891-2897.

[43] D. Mohn, N. Doebelin, S. Tadier, R.E. Bernabei, N.A. Luechinger, W.J. Stark, M. Bohner, J. Mater. Chem. 21 (2011) 13963-13972.

[44] Z. Zou, X. Liu, L. Chen, K. Lin, J. Chang, J. Mater. Chem. 22 (2012) 22637-22641.

[45] D. Lee, P.N. Kumta, Mater. Sci. Eng. C 30 (2010) 934-943.

[46] J. Gomez-Morales, J.M.D. Lopez, M. Iafisco, A. Hernandez-Hernandez, M. Prat, Cryst. Growth Des. 11 (2011) 4802-4809.

[47] D.W. Jones, J.A.S. Smith, J. Chem. Soc. (1962) 1414-1420

[48] C.C. Ribeiro, C.C. Barrias, M.A. Barbosa, Biomaterials 25 (2004) 4363-4373.

[49] S. Teng, J. Shi, B. Peng, L. Chen, Compos. Sci. Technol. 66 (2006) 1532-1538.

[50] R. Stulajterova, L. Medvecky, Colloids Surf. A Physicochem. Eng. 316 (2008) 104-109.

[51] A. Shkilnyy, J. Brandt, A. Mantion, O. Paris, H. Schlaad, A. Taubert, Calcium Chem. Mater. 21 (2009) 1572-1578.

[52] S. Mandel, A.C. Tas, Mater. Sci. Eng. C 30 (2010) 245-254.

[53] Q. Ruan, Y. Zhu, Y. Zeng, H. Qian, J. Xiao, F. Xu, L. Zhang, D. Zhao, J. Phys. Chem. B 113 (2009) 1100-1106.

[54] M. Cusack, A. Freer, Chem. Rev. 108 (2008) 4433-4454.

[55] L.R. Frost, J. Sara, Thermochim. Acta 521 (2011) 14-17.

[56] H. Monma, T. Kamiya, J. Mater. Sci. 22 (1987) 4247-4250.

[57] I. Braccini, S. Perez, Biomacromolecules 2 (2001) 1089-1096.

[58] P. Sikorski, F. Mo, G. Skjak-Bræk, B.T. Stokke, Biomacromolecules 8 (2007) 2098-2103. 